\title{
Effect of Durability properties on Geopolymer concrete - A Review
}

\author{
Niveditha $M^{1 *}$ and Srikanth Koniki ${ }^{*}$ \\ ${ }^{1}$ PG student, Civil Engineering Department, GRIET, Hyderabad, India. Email \\ ${ }^{2}$ Associate Professor, Civil Engineering Department, GRIET, Hyderabad, India. Email: sri.sri001@gmail.com
}

\begin{abstract}
Geopolymer concrete is prepared by reacting silicate as well as aluminate consisting materials with a caustic activator. More often, waste materials such as GGBS, fly ash, slag from metal and iron production are used. Recent investigations adding new materials like Alccofine, which improves the properties of geopolymer concrete even at ambient temperature condition. This research paper presents a details literature survey on the durability properties of geopolymer concrete. Various research literatures are previewed on durability of geopolymer concrete with the addition of different supplementary cementious materials as their necessity is increasing due to insistent constituents. Past studies from the literature reviews suggested that replacement of cement with chemical and mineral admixtures enhanced the properties of strength and durability of concrete. The micro structures, Morphological structures by SEM, lower shrinkage, higher mechanical strengths, superior durability with environmental sustainability are observed. XRD studies shown enhanced polymerisation reaction which is responsible for development of strength. Elevated temperatures and Surface deterioration are controlled in GPC than OPC. Geopolymer concrete provides better resistance for specimens to chemical attack and also water absorption, sorptivity, porosity have good influence to the durability properties in ambient curing conditions compared to conventional concrete.
\end{abstract}

\section{Introduction}

Concrete is the reliable, durable and versatile material used for construction. Concrete requires huge quantities of Portland cement and it is highly used material in the world, next to the water. The cement production consumes large amount of energy and it also generates huge amount of carbondioxide into the atmosphere which leads to the global warming and emission of greenhouse gases effecting the environment [1]. For reducing the emission of carbon dioxide, the alternative binding systems with waste materials like flyash, GGBS, BRHA, slag, nano silica, Etc are used to prepare concrete by eliminating cement is called as "Geopolymer concrete", which is manufactured by stimulating source materials like alumino silicates in a highly alkaline solution[1,2].

The name geopolymer was firstly coined by a French Professor Davidovits in 1978 representing wide range of thermally activated natural materials such as Meta kaolin or byproducts of Industries such as flyash, slag adding a source of silicon ( $\mathrm{Si}$ ) and Aluminium (Al) which dissolves in alkaline solution and polymerises into molecular chains to produce the binder. GGBS is the industrial waste and the BRHA is agrowaste, by keeping the GGBS as a base material and replacing BRHA at different percentages, resulted that the effects of compressive strength, flexural strength and tensile strength are improved and also other durability properties like resistance to accelerated corrosion, sorptivity, chloride permeability are improved [3].Geopolymer gained tremendous importance as an alternative to the binders of ordinary Portland cement as they are possessing very early strength, hardness, chemical stability, better durability without any dangerous alkaliaggregate reaction. The ordinary Portland cement gets easily soluble in acid environment as it contains high content of Cao which makes the cement vulnerable [4].

Various researches worked mostly on flyash based geopolymer on the strength variation and mix proportion. Out of all the supplementary cementious materials the flyash, GGBS are widely used for replacement as they enhance the engineerin $1 \mathrm{~g}$ properties and other materials are used for Reuse or Reutilization of resources. Rice husk ash as substituent intensifies the polymerisation reaction to developed the strength which can be observed by fluorescent optical microscopy and XRD studies [5]. The service life and durability of a structure depends on properties like sorptivity, diffusivity, permeability as it controls the aggressive environment, deteriorations and alkali activated slag-based GPC has been reported to possess the superior durability in aggressive conditions

\footnotetext{
${ }^{1}$ Niveditha M: Nivedithamadanala@gmail.com

${ }^{2}$ Srikanth Koniki: sri.sri001@gmail.com
} 
[6]. The geopolymer paste which includes nano silica and nano aluminium oxide in it for high calcium based flyash yielded good strength and durability properties for particular molar concentration [7]. GPC possess the ideal properties such as freeze-thaw resistance, lower shrinkage. Corrosion and sulphate resistance. It remains sound without need of any repair [8]. The past studies conducted to assess the effects of water absorption, apparent porosity and sorptivity for improving the durability of different flyash based geopolymer concrete motors in sulphuric acid in an accelerated test condition [9]. As the geopolymer binder is a cementious material with low- $\mathrm{CO} 2$, in the process of generating $\mathrm{CO} 2$ it does not confide on the Calcination of limestone, which decreases the emission of $\mathrm{CO} 2$ up to $80 \%$ which is provoked by the cement and aggregate industries [10]. The main concern for serviceability and durability of the geopolymer materials is sulphate attack. Previous experience with Portland cement and blended cement concretes showed cases of concrete deterioration when exposed to sulphate attack in the environment. Previous publications on geopolymer materials investigated the effect of curing procedures, water/binder ratio and composition of the alkaline solution on strength development and hydration products. The arrangement, development and properties of the geopolymer products consisting of flyash depends intensely with respect to virtue and grouping of alkali solutions, alkali activators and on curing conditions. The progressions of $\mathrm{Si} / \mathrm{Al}$ proportions, can prompt the development of various gels. The GPC has altogether higher resistance in consolidating silica fume in the sulphuric acid, chloride solution and it is economically benefitting over the PCC [11].

\section{Necessity of GPC}

In our developing industry, cement is the principle material for the production of the concrete. As the cement helps in creating wide range of helpful shapes with ease, its demand is highly increasing. The production of OPC not just devours critical measures of natural resources yet in addition discharges considerable amount of carbondioxide into the environment. In production of ton of cement huge amount of carbondioxide is emitted which leads to the pollution and also requires 1.6tons of raw materials. So, to overcome such issues, we need to utilize ecological concretes by replacing the conventional concretes with modern results. In this regard, the new innovation GPC is a promising method, which can be formed by using the Industrial wastes. We can reduce the usage of cement by using wastes from thermal industry and chemical refineries which forms GPC and this geopolymer concrete has improved durability characteristics on acid attacks and resistance to high elevated temperatures $[1,16]$.

\section{Significance of the study}

Geopolymer substances are discovering its approaches towards substituting conventional construction components, yet at the same time, different investigations are constrained to heat curing conditions. The extent of acceptance of geopolymer materials which are concrete and motor, can be extended in the event that they can economically and appropriately can be advanced at ambient curing conditions. The ongoing improvement in geopolymer materials with the consideration of different mineral admixtures for improving the properties of durability such as water absorption, sorpitivity, controlling elevated temperatures, Acid resistance, chloride permeability. GPC possess greater resistance towards heat and inorganic solvents, also this has better workability and high compressive strength $[1,12]$.

\section{Study on tests of durability on GPC}

\subsection{Sorptivity}

This test is developed by Hall (1981) which is formed based on Darcy's law of unsaturated flow. Sorptivity is a quick and basic test to determine the capacity of concrete absorbing water in uni-directional, by capillary action on homogeneous material. When compared to control concrete the water absorption rate of geopolymer for sorptivity is less. Specimen with lesser sorpitivity yields greater compressive strength and capillary sorptivity has greater resistant to water absorption of alkali activated slag concrete and reduces the concrete's pore radius $[13,15,16]$.

\subsection{Water absorption}

The main characteristics for durability of concrete is water absorption. This test is performed to assess the water retention qualities and evaluate water penetrability. GPC has less water absorption, and less porosity as the geopolymer materials are finer than control concrete components [13]. The specimen with lesser water absorption yields greater compressive strength. Increasing of sodium hydroxide and sodium silicate content improves the water absorption in specimen which are cured at ambient temperature. High proportions of alkali/binder results in increasing of water absorption $[4,17]$.

\subsection{Porosity}

The microstructural properties of particles with silica content, calcium content and of flyash, significantly affect the porosity. As the permeability of concrete increases the porosity of concrete also increases and shows that the durable concrete should possess low permeability. Generally, this tests the accessible voids and the volume percent of the structure. Specimen with lesser porosity yields greater compressive strength [4]. The pore size decreases with the decrease in porosity of specimen which affects water absorption. The structure of specimen become 
harder, denser and that morphological structure of pores of geopolymer paste can be disclosed by Scanning Electron Microscope (SEM) morphology. Durability can be improved by the decrease in porosity and permeability [18]. In the geopolymer mortars apparent porosity increases by adding silica fumes in flyash based geopolymer pastes [19].

\subsection{Acid test}

Geopolymer concrete has really high resistance towards acid attacks, even after immersion of the specimens for 90days in the different volumes of sulphuric acid solutions it remained undamaged but PPC will be deteriorated with the external surface damage. The geopolymer reactions formed by adding source materials to the $\mathrm{NaOH}$-silicate based activator solutions, enhanced high grade concrete structures by self-curing mechanism [20]. GPC attains high early strength compared to OPC and its very helpful and advantageous concrete material in both strength as well as durability properties especially in resisting acid attacks [21]. Increasing the dosage of activator of flyash based geopolymer materials gives the high compressive strength and high acid resistance [22]. The capacity of acid resistance of hardened mass increases on adding silica fumes [23]. Even after being in $10 \%$ of nitric acid for 24 weeks the geopolymer materials regain their integrity, shape and also good residual compressive strength [24]. The Specimens with lesser content of $\mathrm{Na}_{2} \mathrm{O}$ in nitric acid has shown greater loss of weight [25].

\subsection{Rapid Chloride permeability test}

The RCPT was developed by Whiting (1989) and later formed as ASTM C1202 test and AASHTO T277 for especially testing the chloride penetration [26]. As the concentration of $\mathrm{NaOH}$ solution and measure of $\mathrm{Na}_{2} \mathrm{SiO}_{3}$ content increases, there will be linear decrement in chloride penetration of geopolymer concretes [27]. Using of high content of alkaline activator solutions which are highly conductive, can lead to high permeability of chlorine in GPC. So, it is necessary that RCPT is conducted only after proper geopolymerisation has took place, and the matrix has to be chemically reactive [26].

\section{Future scope of the study}

An effort has been made to accomplish the feasibility of Geopolymer concrete over OPC. To build the awareness of modern techniques like the usage of Geopolymer concrete which are ecological and economical and more durable comparing to the conventional concrete. Furtherly, extensions to this work can be done by examining the durability and mechanical properties including mineral admixtures and also in permeability characteristics. Investigations can be done by inspecting the differences in geopolymer motor cured at ambient temperature and the concrete which prepared in controlled laboratory, field conditions.

\section{Conclusion}

From the studies, the reviews are concluded as follows:

- Geopolymer durability is exhibited by examining the pore structure.

- Geopolymer shows comparatively lesser strength loss and mass loss when compared to $\mathrm{OPC}$ and it yields high resistance to heat and acid attacks.

- The durability properties of geopolymer concretes enhances with time, filling the voids and cracks as it consists of the fine materials.

- GPC can be adequately used in the precast industries, as a result of its high early strength.

- GPC shows superior durability performance compared to OPC when exposed to the acid and chemical attacks.

- Geopolymer concrete is proved as better wear and tear resistance to the acidic atmospheres.

\section{References}

1. Aleem, M. A., \& Arumairaj, P. D. (2012). Geopolymer concrete-a review. International journal of engineering sciences \& emerging technologies, 1(2), 118-122.

2. Singh, A. K. (2016). Strength and Durability Test of Fly Ash and GGBS Based Geopolymer Concrete. Int. Journal of Engineering Research and Application ISSN, 2248-9622.

3. Venkatesan, R. P., \& Pazhani, K. C. (2016). Strength and durability properties of geopolymer concrete made with ground granulated blast furnace slag and black rice husk ash. KSCE Journal of Civil Engineering, 20(6), 2384-2391.

4. Thokchom, S., Ghosh, P., \& Ghosh, S. (2009). Effect of water absorption, porosity and sorptivity on durability of geopolymer mortars. ARPN Journal of engineering and Applied Sciences, 4(7), 28-32.

5. Naspuri Arun Raju, T. Suresh Kumar, International Journal of Innovative Technology and Exploring Engineering, Vol. 8 no. 11, pp: 3860-3864, (2019).

6. Lavanya, G., \& Jegan, J. (2015). Durability study on high calcium fly ash based geopolymer concrete. Advances in Materials Science and Engineering, 2015.

7. Adak, D., Sarkar, M., \& Mandal, S. (2014). Effect of nano-silica on strength and durability of fly ash based geopolymer mortar. Construction and Building Materials, 70, 453-459.

8. Raijiwala, D. B., Patil, H. S., \& Kundan, I. U. (2012). Effect of alkaline activator on the strength 
and durability of geopolymer concrete. Journal of Engineering Research and Studies, 3(1), 18-21.

9. Thokchom, S., Ghosh, P., \& Ghosh, S. (2011). Durability of fly ash geopolymer mortars in nitric acid-effect of alkali (Na2o) content. Journal of Civil Engineering and Management, 17(3), 393-399.

10. Anchula Nagarjuna, T. Suresh Kumar, B.Yogeswara Reddy, M.Udaykiran, International Journal of Innovative Technology and Exploring Engineering, Vol. 8 no. 11, pp: 640-645, (2019).

11. Okoye, F. N., Prakash, S., \& Singh, N. B. (2017). Durability of fly ash based geopolymer concrete in the presence of silica fume. Journal of cleaner Production, 149, 1062-1067.

12. Jindal, B. B. (2019). Investigations on the properties of geopolymer mortar and concrete with mineral admixtures: A review. Construction and Building Materials, 227, 116644.

13. Luhar, S., \& Khandelwal, U. (2015). A study on water absorption and sorptivity of geopolymer concrete. SSRG Int. J. Civil Eng., 2(8), 1-10.

14. Thunuguntla, C. S., \& Rao, T. G. (2018). Effect of mix design parameters on mechanical and durability properties of alkali activated slag concrete. Construction and Building Materials, 193, 173-188.

15. JayShankar, T. N., \& Nagaraja, P. S. (2018). Evaluation of Water Absorption and Sorptivity Properties of Fly Ash, GGBS, M-Sand Based Glass Fibre Reinforced Geopolymer Concrete.

16. Purushotham, P., Prasad, M. H., \& Naveen, P. (2017). A study on green concrete.

17. Huseien, G. F., Mirza, J., Ismail, M., Hussin, M. W., Arrifin, M. A. M., \& Hussein, A. A. (2016). The effect of sodium hydroxide molarity and other parameters on water absorption of geopolymer mortars. Indian Journal of Science and Technology, 9(48), 1-7.

18. Farhana, Z. F., Kamarudin, H., Rahmat, A., \& Al Bakri, A. M. (2015). The relationship between water absorption and porosity for geopolymer paste. In Materials Science Forum (Vol. 803, pp. 166172). Trans Tech Publications Ltd.

19. Thokchom, S., Dutta, D., \& Ghosh, S. (2011). Effect of incorporating silica fume in fly ash geopolymers. World Academy of Science, Engineering and Technology, 60, 243-247.

20. Rajamane, N. P., Nataraja, M. C., Lakshmanan, N., Dattatreya, J. K., \& Sabitha, D. (2012). Sulphuric acid resistant ecofriendly concrete from geopolymerisation of blast furnace slag.

21. Shraddha, P. S., \& Madhuri, M. Compative Study on Acid Resistance of Geopolymer Concrete to Conventional Concrete.

22. Aiken, T. A., Kwasny, J., Sha, W., \& Soutsos, M. N. (2018). Effect of slag content and activator dosage on the resistance of fly ash geopolymer binders to sulfuric acid attack. Cement and Concrete Research, 111, 23-40.
23. Dave, S. V., Bhogayata, A. C., \& Arora, N. K. DURABILITY STUDY OF GEOPOLYMER CONCRETE CURED AT AMBIENT TEMPERATURE.

24. Thokchom, S., Ghosh, P., \& Ghosh, S. (2011). Durability of fly ash geopolymer mortars in nitric acid-effect of alkali (Na2o) content. Journal of Civil Engineering and Management, 17(3), 393-399.

25. Thokchom, S., Ghosh, P., \& Ghosh, S. (2009). Acid resistance of fly ash based geopolymer mortars. International Journal of Recent Trends in Engineering, 1(6), 36.

26. Tummala Suresh Kumar, Kosaraju Satyanarayana, Materials Today: Proceeding, 26 (2), 3228-3233, (2020).

27. Shaikh, F. U. (2014). Effects of alkali solutions on corrosion durability of geopolymer concrete. Advances in concrete construction, 2(2), 109. 